\title{
A review on additive manufacturing of ceramic materials based on extrusion processes of clay pastes
}

\section{(Revisão sobre manufatura aditiva de materiais cerâmicos por extrusão de massas à base de argilas)}

\author{
A.Ruscitti ${ }^{1 *}$, C.Tapia ${ }^{I}$, N. M.Rendtorff ${ }^{2,3}$ \\ ${ }^{1}$ Universidad Nacional de Lanús, 29 de Septiembre 3901, Remedios de Escalada (1826), Buenos Aires, Argentina \\ ${ }^{2}$ Universidad Nacional de La Plata, Facultad de Ciencias Exactas, Departamento de Química, Buenos Aires, Argentina \\ ${ }^{3}$ Centro de Tecnología de Recursos Minerales y Cerámica, CIC-CONICET, Buenos Aires, Argentina
}

\begin{abstract}
This paper aims to present a state of the art of additive manufacturing (AM) of ceramic materials based on extrusion processes of clay pastes, reviewing the definitions and classifications of the AM field under current international standards. A general overview on the AM category 'material extrusion' is provided and the class 'paste deposition modeling' is proposed for those techniques based on the extrusion of pastes that are solidified by solvent vaporization, with the aim of distinguishing it from the class 'fused deposition modeling', which is applied to extruded polymers through temperature plasticization. Based on the survey of background information on $3 \mathrm{D}$ printing technology by ceramic paste extrusion, a classification and historization of the innovations in the development of this technology are proposed.

Keywords: 3D printing, additive manufacturing, extrusion, ceramics.
\end{abstract}

Resumo

O presente trabalho apresenta uma revisão do estado da arte de manufatura aditiva (MA) de materiais cerâmicos baseada nos processos de extrusão de massas à base de argilas, repassando as definições e a classificação do campo de MA de acordo com as normas internacionais. Descreve-se a categoria de MA 'extrusão de material' em aspectos gerais e propõe-se a classe 'modelagem por deposição de pasta' para as técnicas baseadas em extrusão de massas que solidificam por evaporação do solvente, com o intuito de diferenciar do termo 'modelagem por deposição de material fundido', que é utilizado para polímeros extrudados por meio de plastificação a quente. A partir do levantamento dos antecedentes da tecnologia de impressão $3 D$ por extrusão de massas cerâmicas, propõe-se uma classificação e historização das inovações no desenvolvimento desta tecnologia.

Palavras-chave: impressão 3D, manufatura aditiva, extrusão, cerâmicas.

\section{INTRODUCTION}

After an initial phase of development as cutting-edge technology during the last decades of the $20^{\text {th }}$ century, $3 \mathrm{D}$ printing technologies greatly expanded at the turn of the new century as a result of the diffusion of these innovations [13]. This process has been characterized by: i) high levels of progress in the Science and Technology (S\&T) fields; ii) incorporation of digital tools in the industrial design and production cycle; iii) growing market interest that has led this process to become an industrial sector with its own economic weight; iv) consolidation of community and global networks of use, application, development, and experimentation arising under the open innovation model within the context of digital globalization; v) its popularization in culture, as the materialization of the representations of imaginary future of science-fiction, with the controversy emerging

*aruscitti@unla.edu.ar

Dhttps://orcid.org/0000-0002-7683-1009 between the renewed promise of technological progress and the social concern for the tensions generated by disruptive technologies; and vi) the opportunities it offers for local development and its inclusion in the list of priority scientific and technological challenges to be addressed by innovation and educational public policies. While consolidating itself as an emerging technology, 3D printing technology started to be defined by its capacity of manipulating matter digitally, by 'moving from the bit to the atom and vice versa', also understood as the continuation of digitization from the field of information and communication to that of the production of objects [4].

In this article, our aim is to perform a review of additive manufacturing (AM) by extrusion of clay-based ceramic materials in order to clarify the definitions and describe the particular features of this new technology. For this purpose, we conducted a survey of recent experiences carried out in laboratories, virtual communities, and the private sector by addressing the academic literature, the information shared in open knowledge networks, and the technical and commercial 
documentation of companies. We then selected the most representative cases and performed a comparative analysis that allowed us to establish a chronology of the evolution of technological development and propose an orderly classification of the background information surveyed. Finally, the main research and development challenges for the consolidation of this emerging innovative sector are outlined.

\section{DEFINITION AND CLASSIFICATION OF ADDITIVE MANUFACTURING}

In its brief history, several conceptualizations of AM phenomenon have been used, employing their own, often ambiguous, and confusing terminologies. Some of the terms used were additive fabrication, additive processes, additive techniques, additive layer manufacturing, layer manufacturing, solid freeform fabrication, freeform fabrication, among others. In 2015, the ISO/ASTM 52900 standard established a clear framework for additive manufacturing, defining it as the "process of joining materials to make parts from 3D model data, usually layer upon layer, as opposed to subtractive and formative manufacturing methodologies", and $3 \mathrm{D}$ printing as the "fabrication of objects through the deposition of a material using a printhead, nozzle, or another printing technology" [5]. The process involved in the digital manufacturing of a part, as shown in Fig. 1, is conducted in different steps within a system, in whose core is the actual printing machine, where the construction process takes place based on the successive addition of material in the form of layers, which is precisely what distinguishes AM from subtractive and formative methodologies. The previous actions are those carried out on the 3D model data in software that allows the solid part to be sectioned in successive planes and calculate the necessary trajectories based on the loading of the parameters by the operator. After 3D printing, several operations are performed that may involve modifications to the properties of the material or the termination of the workpiece geometry.

The particular way in which the various additive techniques solve the additive construction cycle characterizes each one; therefore, the main criterion to categorize them is the technological methodology adopted, considering the following criteria [6]: according to the type of geometric element used as a module (point, line, and plane); characterizing the material not so much for its composition but for its state and presentation as a process input (liquid, suspension, powder, sheet, paste, filament); and according to the method used to join it (sintering/fusion, polymerization, lamination, extrusion, and deposition by injection). The ISO/ASTM 52900 standard establishes a general classification, organizing the vast AM universe into seven categories [5]: i) binder jetting: process in which a liquid bonding agent is selectively deposited to join powder materials; ii) direct energy deposition: process in which focused thermal energy is used to fuse materials by melting

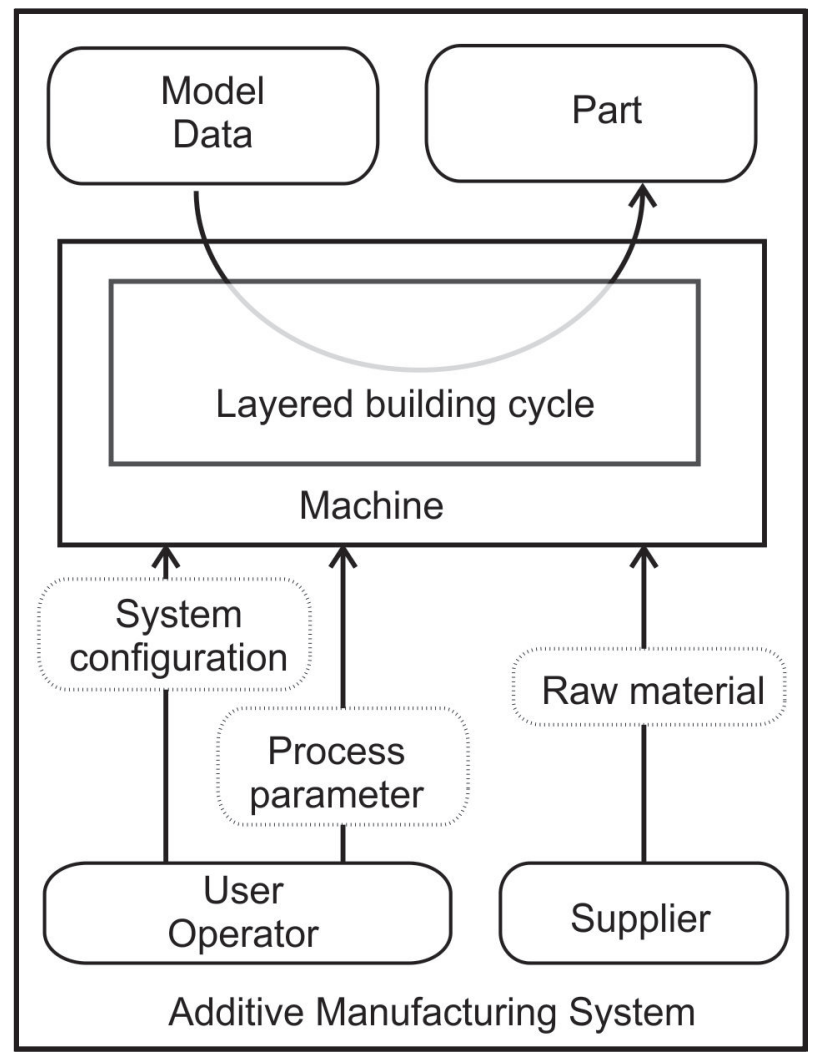

Figure 1: Additive manufacturing (AM) system in the process of manufacturing a part from a 3D data model (based on ISO/ASTM 52900 [5]).

[Figura 1: Sistema de manufatura aditiva (MA) no processo de fabricação de uma peça a partir de um modelo de dados $3 D$ (baseado na ISO/ASTM 52900 [5]).]

as they are being deposited; iii) material extrusion: process in which material is selectively dispensed through a nozzle or orifice; iv) material jetting: process in which droplets of build material are selectively deposited; v) powder bed fusion: process in which thermal energy selectively fuses regions of a powder bed; vi) sheet lamination: process in which sheets of material are bonded to form a part; and vii) vat photopolymerization: process in which a liquid photopolymer in a vat is selectively cured by lightactivated polymerization. Within each category, Table I shows the second level of classification that responds to the denominations that the manufacturers gave to the particular operation principle of their equipment.

Ceramic materials are used in several AM categories. In other reviews, it can be observed that the techniques based on ceramic powders and suspensions are the ones that achieve the best results in dimensional aspects and in harnessing the potential of advanced materials in high valueadded applications [6, 8-10]. Within the material extrusion (ME) category, there are investigations in non-clay ceramic materials; however, the techniques involving the clay paste-based extrusion of traditional materials are the most widespread in design, art, and industry, due to their low-cost and the impulse of the open innovation movement. Due to the fact that AM has been created in social networks rather 
Table I - Additive manufacturing categories (based on [7]).

[Tabela I - Categorias de manufatura aditiva (baseadas em [7]).]

\begin{tabular}{|c|c|c|c|c|}
\hline Category & Class & & Material & Supplier \\
\hline \multirow{5}{*}{$\begin{array}{c}\text { Vat } \\
\text { photopolymerization }\end{array}$} & \multirow{2}{*}{ Stereolithography } & \multirow{2}{*}{ SLA } & Plastic & 3DSystems, Formlabs, DWS \\
\hline & & & Ceramic & 3Dceram \\
\hline & \multirow{2}{*}{$\begin{array}{l}\text { Digital light } \\
\text { processing }\end{array}$} & \multirow{2}{*}{ DLP } & Plastic & EnvisionTec, B9Creations \\
\hline & & & Ceramic & Adamtec, Ceraform100, Ceramco, Lithoz \\
\hline & $\begin{array}{l}\text { Continuous digital } \\
\text { light processing }\end{array}$ & CDLP & Plastic & Carbon3D, EnvisionTec \\
\hline \multirow{2}{*}{ Material extrusion } & $\begin{array}{l}\text { Fused deposition } \\
\text { modeling }\end{array}$ & FDM & $\begin{array}{l}\text { Plastic, glass, } \\
\text { composite }\end{array}$ & $\begin{array}{l}\text { Stratasys, Ultimaker, MakerBot, Zortrax, } \\
\text { Prusa, Printrbot, Markforged }\end{array}$ \\
\hline & $\begin{array}{l}\text { Paste deposition } \\
\text { modeling }\end{array}$ & PDM & $\begin{array}{l}\text { Ceramic, } \\
\text { concrete }\end{array}$ & $\begin{array}{c}\text { (see sub-section Evolution below for } \\
\text { ceramic) }\end{array}$ \\
\hline \multirow{3}{*}{ Material jetting } & Material jetting & MJ & Plastic & Stratasys, 3DSystems \\
\hline & $\begin{array}{l}\text { Nanoparticle } \\
\text { jetting }\end{array}$ & NPJ & Metal, ceramic & XJet \\
\hline & Drop on demand & DOD & Wax & Solidscape \\
\hline Binder jetting & Binder jetting & BJ & $\begin{array}{l}\text { Gypsum, sand, } \\
\text { metal, ceramic }\end{array}$ & $\begin{array}{l}\text { 3DSystems, Voxeljet, Kwambio, D-Shape, } \\
\text { ExOne }\end{array}$ \\
\hline \multirow{4}{*}{ Powder bed fusion } & Multi jet fusion & MJF & Plastic & $\mathrm{HP}$ \\
\hline & $\begin{array}{l}\text { Selective laser } \\
\text { sintering }\end{array}$ & SLS & Plastic & EOS, 3DSystems, Sinterit, Sintratec \\
\hline & $\begin{array}{l}\text { Selective laser } \\
\text { sintering }\end{array}$ & SLM & Metal & $\begin{array}{l}\text { EOS, 3DSystems, SLM Solutions, } \\
\text { Renishaw, ConceptLaser }\end{array}$ \\
\hline & $\begin{array}{l}\text { Electron beam } \\
\text { melting }\end{array}$ & EBM & Metal & Arcam \\
\hline \multirow{2}{*}{$\begin{array}{l}\text { Direct energy } \\
\text { deposition }\end{array}$} & $\begin{array}{l}\text { Laser engineering } \\
\text { net shape }\end{array}$ & LENS & Metal & Optomec \\
\hline & $\begin{array}{c}\text { Electron } \\
\text { beam additive } \\
\text { manufacturing }\end{array}$ & EBAM & Metal & Sciaky \\
\hline Sheet lamination & $\begin{array}{l}\text { Laminated object } \\
\text { manufacturing }\end{array}$ & LOM & $\begin{array}{l}\text { Composite, } \\
\text { paper }\end{array}$ & Mcor, EnvisionTec \\
\hline
\end{tabular}

than as a result of academic research and development, it is presented as a vacant field to be analyzed with the aim to propose an organized and consistent classification criterion.

\section{D PRINTING BY CERAMIC PASTE EXTRUSION}

The main class of the material extrusion (ME) category is known as fused deposition modeling (FDM) and has become the most widespread in industry and amateur and professional use. Used mainly for plastics and polymeric matrix composites, FDM is defined as the technique in which a filament is extruded by melting it using heat and forcing it to pass through a nozzle, which once deposited solidifies upon cooling. In this work, we use the term paste deposition modeling (PDM) to refer to a large number of experiences that use pastes, in the plastic state, for which there is no clear terminology. The process is similar to that of FDM of polymers, except that the paste is extruded and deposited at room temperature, solidifying by evaporation of water or other solvents (Fig. 2). In their 2014 review, Travitzky et al. [6] found several varied denominations for this process: extrusion freeform fabrication (EFF), aqueous-based extrusion fabrication (ABEF), filamentbased writing (FBW), freeze extrusion fabrication (FEF), direct ink writing (DIW), slurry deposition, dispense plotting, bioplotting, rapid prototyping robotic dispensing (RPRD), microextrusion freeforming (MF), multiphase jet solidification (MJS), 3D fiber deposition (3DFD), and robocasting (RC). PDM technology applied in the manufacture of ceramics could replace the usual production techniques of bodies in the green state, the preparation of the input, and subsequent operations, being the same as those of the traditional manufacturing method (Fig. 3). As generally occurs with the digitization of manufacturing processes, the 
main advantages are the elimination of investment and the construction periods of the models, molds, and matrices, the extension of morphological possibilities, and the speed and low production cost of individual pieces or small series.

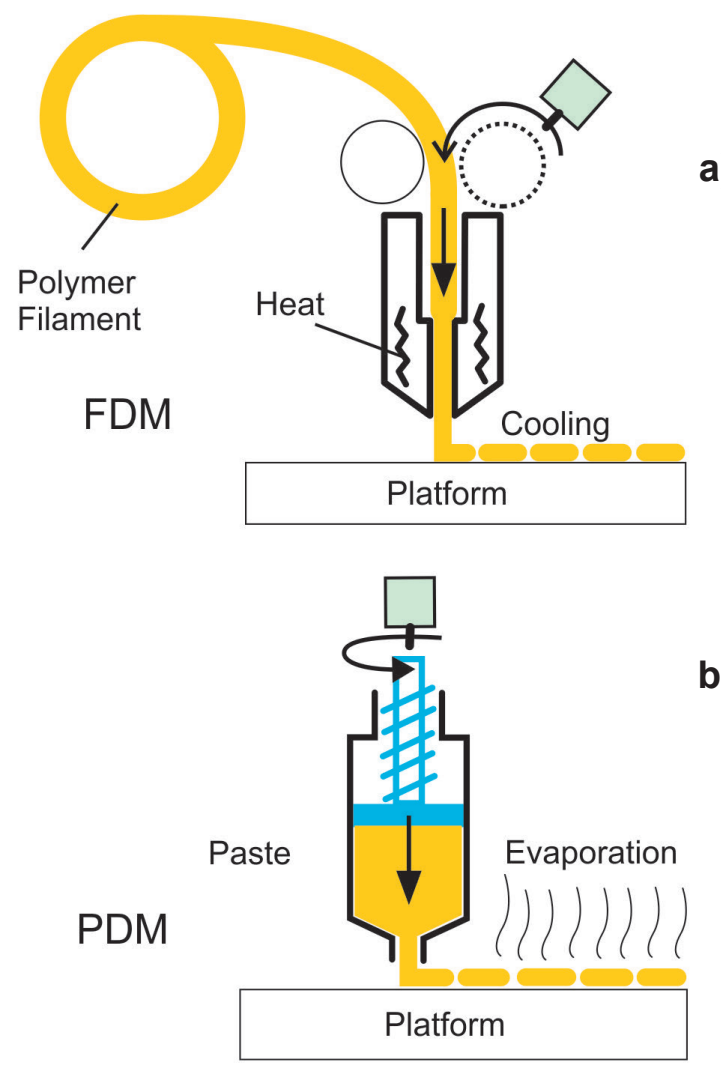

Figure 2: Comparative schematics of fused deposition modeling FDM (a), and paste deposition modeling - PDM (b).

[Figura 2: Ilustrações comparativas de modelagem por deposição de material fundido - FDM (a) e modelagem por deposição de pasta-PDM (b).]

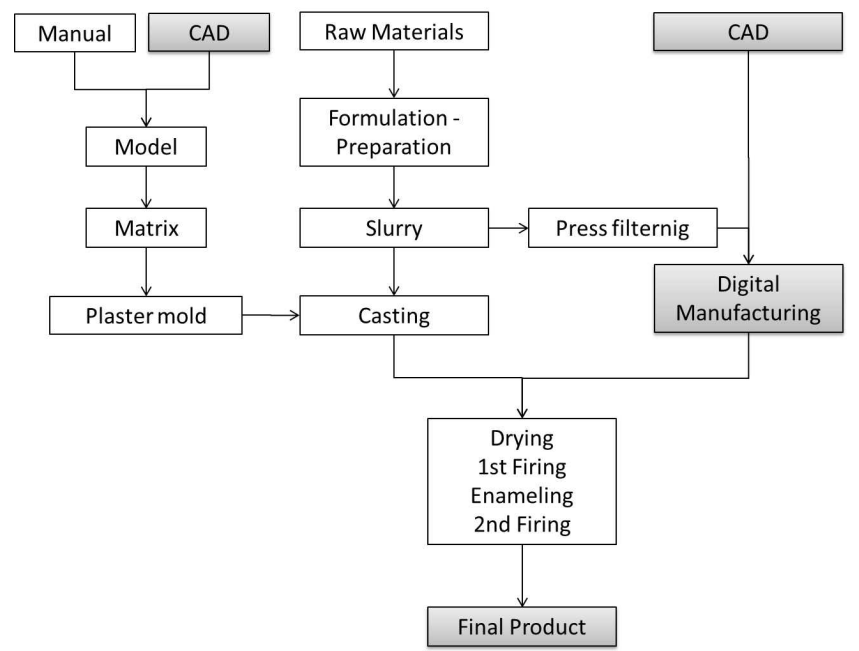

Figure 3: Flowchart of the traditional process of ceramic manufacture by slip casting vs. digital manufacturing process.

[Figura 3: Fluxograma do processo tradicional de fabricação de cerâmica por colagem vs. processo de fabricação digital.]
Operation principle of $3 D$ printing by material extrusion: ME consists in the selective deposition of any material in the plastic state through an orifice, on a platform that supports the first layer, which moves automatically in the space with respect to the nozzle (prismatic in Cartesian printers and cylindrical in delta and SCARA type printers), in an XYZ coordinate system. The material is extruded through the die of the nozzle with a circular cross-section, and when deposited, it adopts an oblong cross-section, which can be described as a rectangle ending in two semicircles for the purpose of calculating its area [11], deforming itself against the platform or the bottom layer (Fig. 4). The height of the deposited material is fixed for each layer by the separation in the $\mathrm{Z}$-axis, and the solid formed by the translational movement of the deposition cross-section is generated by the trajectory of the nozzle thanks to the interpolation of the $\mathrm{X}$ and $\mathrm{Y}$ axes. The width of the deposited cross-section is undoubtedly in relation to the ratio of the extrusion and forward speeds in XY. The control of this relationship is key to ensure both overall dimensional accuracy and thickness of the walls, as well as the homogeneous constitution of a layer by the correct adjacency of the deposited lines. While the geometrical and kinematic variables of the process are set by parameters at the time of programming the process, and, therefore, can be accurately executed, the extrusion flow varies depending on the rheological properties of the material and their behavior in the extrusion device. In order to build volume by material extrusion using filaments of deposited material, the strategy used consists in decomposing the geometry into: i) horizontal layers: a surface is gradually formed by depositing a filament line adjacent to another, in zigzag or concentric form, whose total height is a multiple

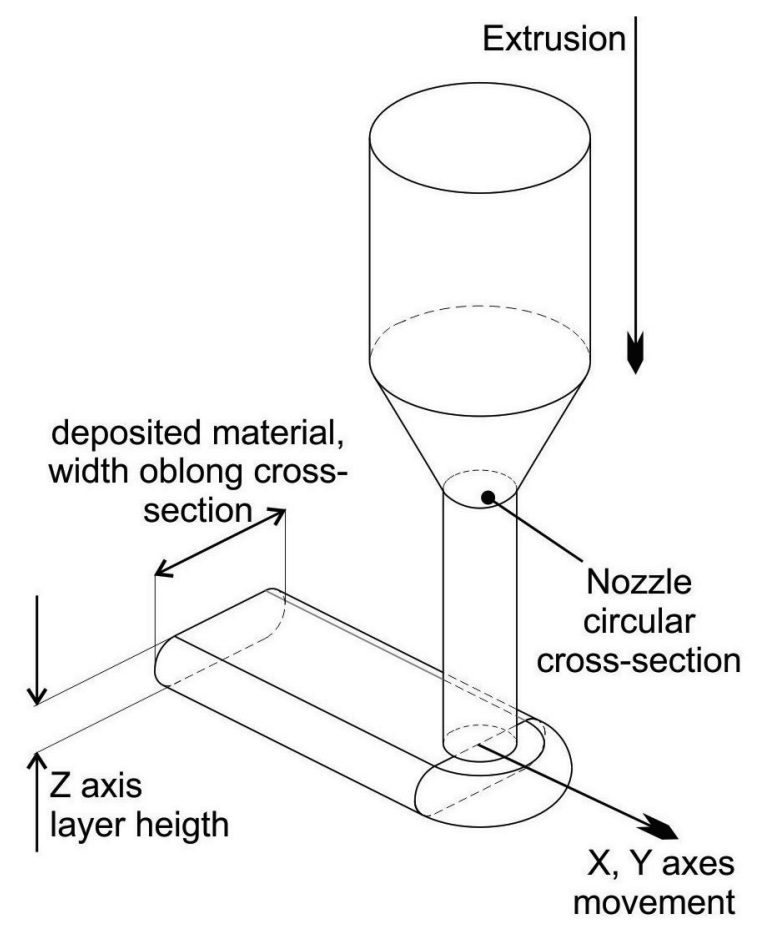

Figure 4: Schematic of extrusion and deposition process. [Figura 4: Esquema do processo de extrusão e deposição.] 
of the height of the layer; ii) vertical walls: a shell is gradually formed by continuously depositing adjacent filament lines along the external or internal perimeters; the shell thickness is a multiple of the filament width; and iii) infill structure: with various patterns, typically zigzag or honeycomb, nonadjacent lines are deposited except for completely solid parts, which make up a grid structure of programmable density.

Critical aspects of the manufacturing process by extrusion and deposition: the uniformity of the part is determined by the correct adhesion of the new material to the previous one. Adhesion between passes occurs by the deformation of the extruded material when pressed onto the material deposited previously. For this purpose, the ratio of extrusion and forward speeds must be such that the deposited cross-section is greater than that of the exit orifice, and the height of the layer is smaller than that of the exit orifice. In addition to the forward movements of the deposition, other auxiliary positioning movements are necessary between the end of one filament and the beginning of another, during which the extrusion must be paused. In order to control this cycle effectively, retraction is used, that is, the movement of the material in the reverse direction that eliminates the pressure remaining in the nozzle, which is the result of the elasticity of the material and of the device. The properties of the material, the height of the layer, and the deposited width determine the minimum angle of the vertical walls with respect to the horizontal plane on which a self-supporting part can be built. Under that condition, the new filament can still be supported by the filament below it; below that minimum, it is necessary to build an auxiliary support structure called support, which must be removed later.

Ceramic pastes for PDM: ceramic pastes consist of homogeneous and heterogeneous systems with solids, water and/or additives. They present a plastic behavior that permits the extrusion or any other plastic deformation-based shaping strategy, like a semi-automatic wheel or slab roller equipment. Solids usually consist of clays and non-clay mixtures. The additives might be polymeric plasticizers and/ or inorganic electrolytes. Plasticizing additives may or may not be added; usually, the rheology of pastes is adjusted by optimizing the milling operations (reducing the grain size) and/or selecting clay components with greater or lesser plasticity [12]. Clay pastes are generally made up of natural raw materials, traditionally clay, quartz, and feldspar, which can be represented by the well-known triaxial diagram; solids are usually incorporated and mixed in a ball mill or a vertical mixer. For plastic forming, mixing is usually carried out by a wet route, and then the water content is adjusted by filter presses or any other moderate drying operation. In general, the suitable rheology for forming in the plastic state is achieved by adjusting the water content [13]. Undoubtedly the rheology of clay-based pastes must be taken into account for the design and use of this type of manufacturing technology. The rheological characteristics of fluid are one of the essential criteria in the development of products in an industrial setting. Frequently, these characteristics determine the functional properties of materials and intervene during quality control, the design of basic operations, such as pumping, mixing, packaging, and storage, and the physical stability, even more in the extrusion. Rheological properties are defined based on the relationship existing between a force or system of external forces and their response, either as deformation or flow. Plasticity in the processing of clay-based materials is a fundamental property since it defines the technical parameters to convert a ceramic mass into a given shape by application of pressure [14]. Plasticity, in this case, and particularly in clay mineral systems, is defined as "the property of a material which allows it to be repeatedly deformed without rupture when acted upon by a force sufficient to cause deformation and which allows it to retain its shape after the applied force has been removed" [14]. A clay-water system of high plasticity requires more force to deform and deforms to a greater extent without cracking than one of low plasticity, which deforms more easily and ruptures sooner [15]. The plasticity of clays is related to the morphology of the plate-like clay mineral particles that slide over the others when water is added, which acts as a lubricant. As the water content of clay is increased, plasticity increases up to a maximum, depending on the nature of the clay.

\section{CLASSIFICATION AND CHRONOLOGY OF THE PDM OF CERAMICS}

To address the state of the art of 3D printing of ceramic materials by paste extrusion, we propose a contrastive analysis between a chronological axis and a typological axis to analyze the selected cases and find the line of evolution of the knowledge produced in the development of this technology.

Chronology: for the classification, we addressed the background information available and selected the most representative experiences that had achieved the best results. Four groups stand out in time among the cases analyzed: i) between 2005 and 2009, the first experimental extruders were developed along with the pioneer open-design and lowcost printers of the RepRap and Fab@Home projects, which were controlled by the open-source code electronics of the Arduino project; ii) since 2009 , the extruders developed by the pioneers grouped in the Google+ community 'Make Your Own Ceramic 3D Printer', which recently moved to the 'Ceramic 3D Printing' forum based in WikiFactory [16], such as Dries Vanderbruegen of the Unfold Studio, Jonathan Keep and more recently Tom Lauerman along with Olivier van Herp; initiatives that have an experimental and exploratory purpose, oriented to artistic production and the manufacture of design objects; iii) since 2014, the first commercial initiatives of new companies supplying industrial-grade equipment began, with much friendlier operating systems and reduced maintenance costs: Lutum, Viscotec, 3DPotter, Wasp, Zmorph, Gaia; and iv) since 2017, a second group of new companies that launched their products on the Kickstarter crowdfunding website, e.g., ClayXYZ, StoneFlower, and CeramBot, with proposals to improve the users' experience to expand the market reach to a non-specialized sector. 
Classification: following the criterium proposed by the ISO standard to analyze and classify the universe of additive manufacturing by extrusion of ceramic paste (Fig. 5), we focused on the methodology or technological approach, specifically on these questions: what are these extruder devices like, what operating principles are they based on, and what technological resolutions do they use? All the processes analyzed are discontinuous or batch-type; that is, the volume of paste available for an operation is fixed and determined by the dimensions of a container. As the way to expand the capacity of the system is to increase the size of the container, and thus, its mass, to avoid increasing the power of the machine, in most cases, the decision is to separate the container from the moving parts. This leads to a first distinction between the devices that perform the extrusion in a single-step process and those that add a first stage of material feeding to a second extrusion stage. Singlestep devices consist of a cylinder or sleeve where the paste is previously loaded and a piston or plunger that forces it to flow through a nozzle. The piston can be operated in two ways: i) pneumatic, with compressed air, such as linear actuators; and ii) mechanic or ram extruder, by the linear force of a motorized screw and nut mechanism. Two-steps devices use the pneumatic or mechanical piston to solve the feeding of materials through a hose to the second step where the extrusion takes place. This last step can be solved using a motorized mechanism of two types: a) conventional screw or Archimedes' screw, in a cylindrical shaft, such as

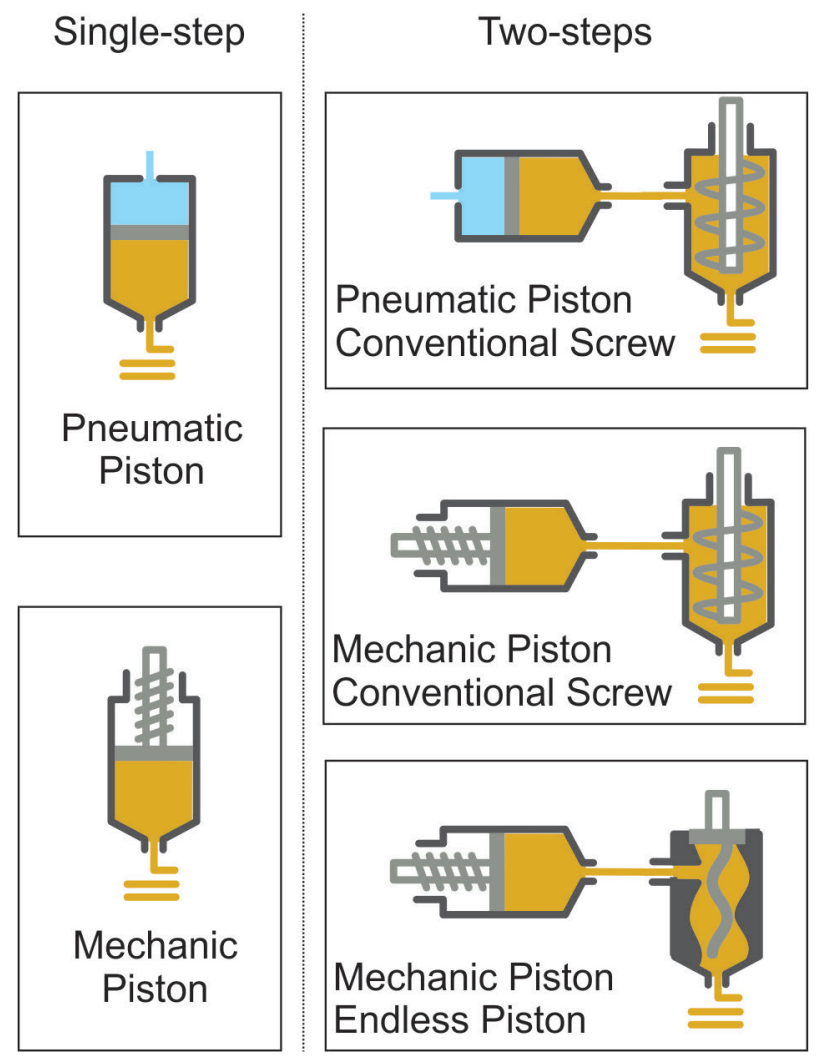

Figure 5: Classification of PDM devices.

[Figura 5: Classificação dos dispositivos de PDM.] that of the extruders of the ceramic industry [17]; and b) endless piston [18], or Moineau pumps [19], such as those in progressive cavity pumps, consisting of a simple helical metal rotor and elastomeric stator with a double helix cavity.

Evolution: in the timeline ordered according to the extruder type (Fig. 6), a search-oriented towards the flow control can be observed as the key for the improvement of morphologies likely to be obtained and thus, expand the potential applications of the technology. Clay-based paste, unlike polymers, behaves as a material with complex, nonNewtonian rheology, which in some cases is affected, not only by the cutting effort but also by the time [20, 21] This wide range of rheologic behavior of the ceramic paste oriented the exploration towards the search for increasingly 'volumetric' mechanisms, in the sense of the principle of positive displacement pumps, an extrusion device capable of delivering a flow unit for a given unit of increased pressure or rotation of the pumping element. Fig. 6 schematically represents the distribution of the cases studied according to their typology and in a timeline. Below, each case is detailed and analyzed, and their main features are described along with the advantages and disadvantages of each type of device.

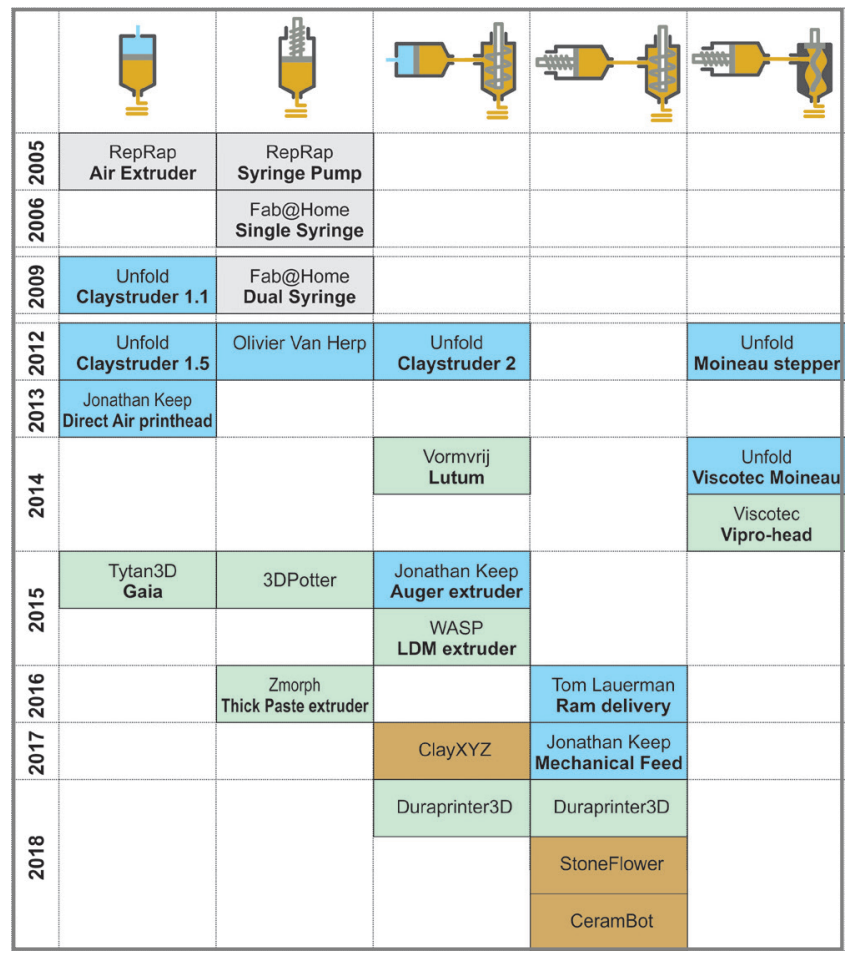

Figure 6: Timeline diagram of PDM extruder types.

[Figura 6: Diagrama de linha do tempo dos tipos de extrusora PDM.]

Single-step pneumatic piston. Air extruder: first pneumatic extruder developed in 2005 by Adrian Bowyer at the start of the RepRap project conducted at the University of Bath in the United Kingdom, by experimenting with simple elements such as a balloon, a plastic bottle, and a solenoid valve controlled from the first electronic $3 \mathrm{D}$ printing control 
plates (Fig. 7a). Even before the development of heated extruders for the extrusion of polymer filaments, which are central in the current 3D printing boom phenomenon, this flagship project involving free hardware and the maker movement tested paste extrusion at room temperature in its first prototypes of low-cost and free design desktop Cartesian 3D printers, the historic Darwin and Mendel models. Claystruder 1.1 and Claystruder 1.5: among the pioneers of ceramic 3D printing, the Belgian Design Studio Unfold is the one that has followed the most systematic approach in "the road to better paste extrusion" [24]. While the interest in paste extruders waned in the maker movement, they developed devices for low-cost desktop printers; in this case, one with a typical work volume of $200 \times 200 \times 200$ $\mathrm{mm}$, also controlled by open access electronics, such as the Arduino Mega 2560 and Ramps plates. In 2009 the studio launched its first version of a pneumatic extruder (Fig. 7b) [25]. It consists of a $60 \mathrm{~cm}^{3}$ syringe mounted on a Cartesian desktop printer using 3D-printed plastic parts, connected to a compressed air pipeline of up to $8 \mathrm{bar}$, such as that obtained with a small workshop compressor. The first version had a solenoid valve to control the extrusion connected to the same electronics of the machine in on-off mode. The second version (Fig. 8a) had no valve but a manually controlled high precision pressure regulator and, therefore, not synchronized to the movements of the printer [28]. Direct air printhead: in 2013, the English ceramist Jonathan Keep published a self-build 3D printer [29], the design of a delta printer for personal manufacturing that had great success for its solidity and constructive simplicity as well as for the clarity of the open-access documentation. A direct compressed air device was the first to be used with this machine. Instead of a syringe, this device harnesses the standard $310 \mathrm{~cm}^{3}$ cartridge system of adhesive dispensing guns (Fig. 8b). Connected to a small compressor of up to 8 bars, it uses its pressure regulator and a manual shut-off valve [29]. Observations: i) the mechanisms of the pneumatic cylinder are of simple construction, easy to clean and handle, and can be scaled and become detached from the printer to have greater capacity, by driving the paste through a hose; ii) they require an external compressed air source, which can be solved with small and accessible commercial compressors as they do not require air flow, a constant pressure being more important; iii) the on-off control of the compressed air circuit can be a manual valve or one activated by a solenoid automatically from the printer electronics; iv) the air pressure control is a membrane regulator of the industrial type, which can be from the same compressor, although a compressor with greater precision is preferable; v) its main disadvantage is the poor precision in extrusion flow control and, therefore, in the repeatability of the printing cycle, due to variations in the viscosity of the paste and extrusion conditions; vi) retraction is not possible although they may have an on-off extrusion control mechanism; vii) they allow to print parts in a single pass with wide tolerance in wall thickness and it is difficult to build bottoms homogeneously; and viii) the paste viscosity must remain within a range that allows it to flow through the sleeve and the nozzle with safe air pressures (up to 8 bar), and so that the piece resulting from the stacking of layers can be supported under its own weight and withstand the platform accelerations.
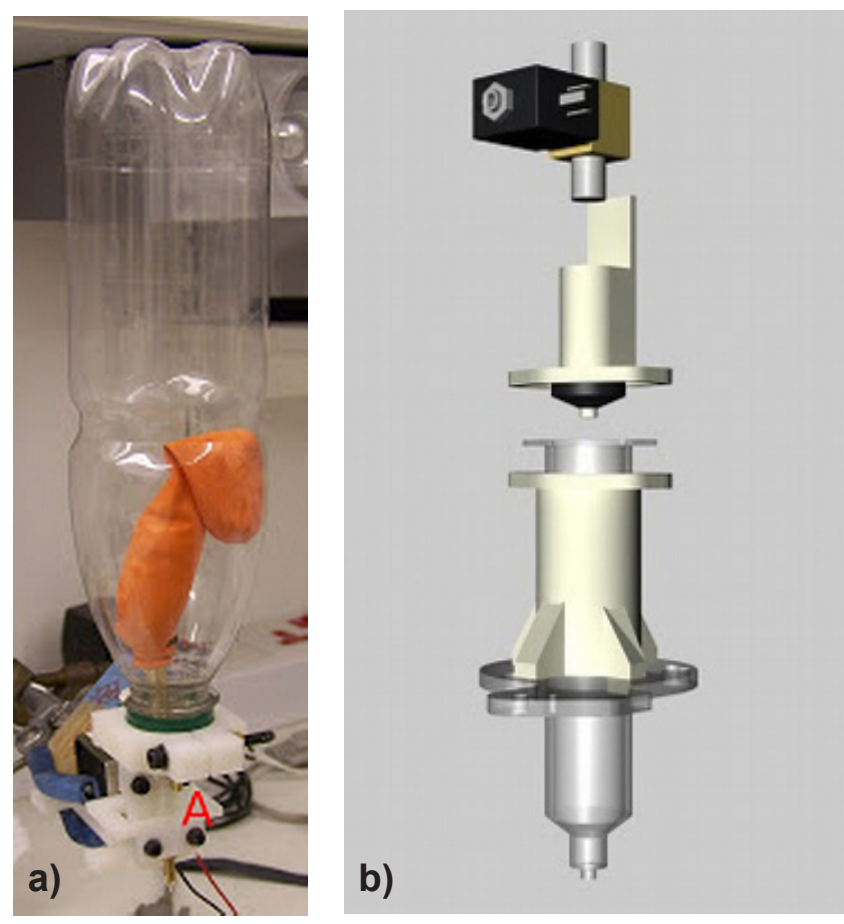

Figure 7: Image of an air extruder (a) [22], and schematic of Claystruder 1.1 (b) [23].

[Figura 7: Imagem de uma extrusora de ar (a) [22] e esquema da Claystruder 1.1 (b) [23].]

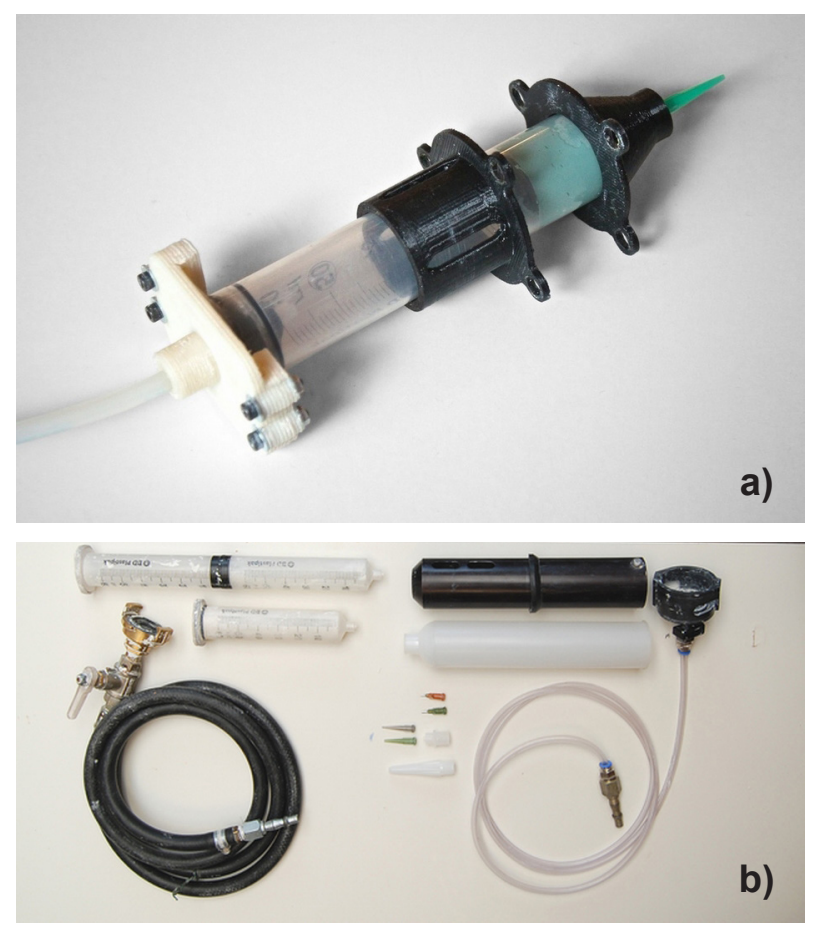

Figure 8: Images of Claystruder 1.5 (a) [26], and direct air printhead (b) [27].

[Figura 8: Imagens da Claystruder 1.5 (a) [26] e cabeçote de impressão pneumática direta (b) [27].] 
Mechanical piston. Syringe pump: the 2005 syringe pump (Fig. 9a) also dates back to the start of the RepRap project. A standard syringe is mounted on a device for 3D printing, and the piston is pushed by a motorized screw nut mechanism. With the same constructive scheme, the Fab@Home Project of Cornwell University in the USA launched model 1 of its extruder in 2006 and model 2 in 2009 (Fig. 9b) [31, 32]. The project ended in 2012 when DIY printers were finally popularized, and the sales surpassed those of industrial printers. Many of their design principles can be found in later models, and during those years, the extruders were the only available ones to experiment with double extrusion and in areas such as bioprinting or food printing. Olivier van Herpt: in 2012, the Dutch industrial designer Olivier van Herpt built his first 3D printer and started a research project that has led him to become one of the main world referential figures for the quality and originality of printed ceramic pieces. He uses a huge delta printer and a high capacity mechanical piston device that allows the production of parts of up to $1000 \mathrm{~mm}$ high and $400 \mathrm{~mm}$ in diameter (Fig. 10a) [33]. 3D Potter: since 2015, the 3D Potter company based in Florida, USA, offers a family of large and high-quality printers. With the aim of using 'real clay' in the process, they built a heavy-duty mechanical piston that can push the paste into cartridges with a capacity of 1000 to $4000 \mathrm{~cm}^{3}$. To solve the problem of the high weight of the device, they decided to integrate it into the vertical Z-axis of a Cartesian printer of relatively slow movements, while the platform is the one that moves along the horizontal $\mathrm{X}$ and $\mathrm{Y}$ axes. With nozzles of 3.5 to $6.4 \mathrm{~mm}$ in diameter, it allows manufacturing pottery pieces with dimensions of up to $508 \times 432 \times 762 \mathrm{~mm}$ (Fig. 10b) [34]. Thick paste extruder: the first reports of the thick paste extruder (Fig. 10c) of the ZMorph company based in the city of Wroclaw, Poland, date back to 2016. Their Zmorph Multitool 3D machine is currently one of the most complete and advanced in industrial quality desktop equipment and user-friendly operation. A set of interchangeable printheads allows its use in laser cutting, CNC machining, and FDM of polymers. The ceramic paste extruder (and other materials such as chocolate, for example) has a $100 \mathrm{~mL}$ capacity, is of robust construction, simple installation, and is equipped with a Nema 17 stepper motor, thus being compatible with low-power electronics. Its work volume is $250 \times 235 \times 165$ $\mathrm{mm}$ [35]. Observations: i) the mechanical piston system meets the condition of being 'volumetric' but limited to the phenomenon of elasticity of the same device and of the paste; ii) the inherent compressibility of the clays, the possible incorporation of air into the paste, and the deformation of the cartridge by internal pressure cause a delay between the motor action and the extrusion reaction in the nozzle; iii) that delay in the extrusion control must be solved in the program configuration; the paste viscosity must be such as to maintain a resistance that does not put a strain on the motor beyond its safe range; the commercial pastes require high torque equipment with gearboxes and power electronics; iv) in the Zmorph and 3D Potter cases, the extrusion control is synchronized with an open control loop with the printer electronics so that, compensating the elasticity by program, it would be possible to obtain multi-pass wall pieces and homogeneous bottoms; and v) in Olivier van Herpt's case, the high power device is not synchronized to the printer, it is limited to single-pass pieces; however, it produces pieces of remarkable quality, leading the vanguard in the creation of a new morphological repertoire for this new technology.
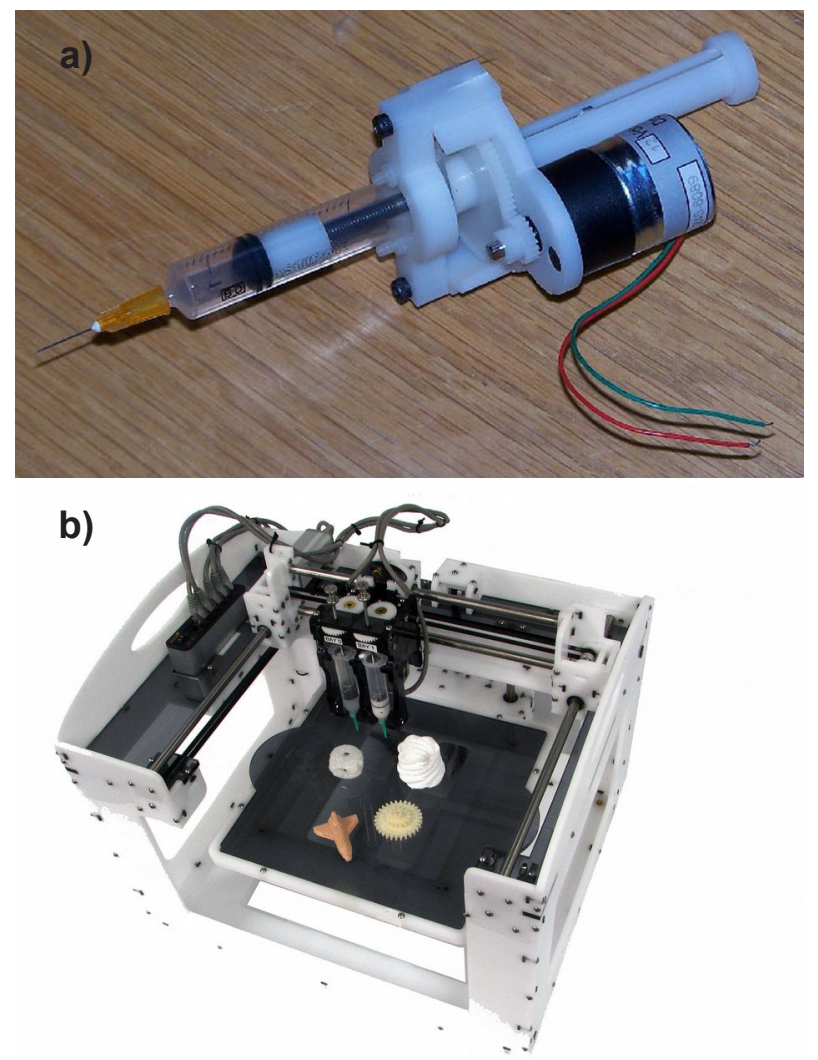

Figure 9: Images of syringe pump (a) [22], and Fab@Home dual syringe printer (b) [30].

[Figura 9: Imagens da bomba de seringa (a) [22] e da impressora com seringa dupla Fab@Home (b) [30].]
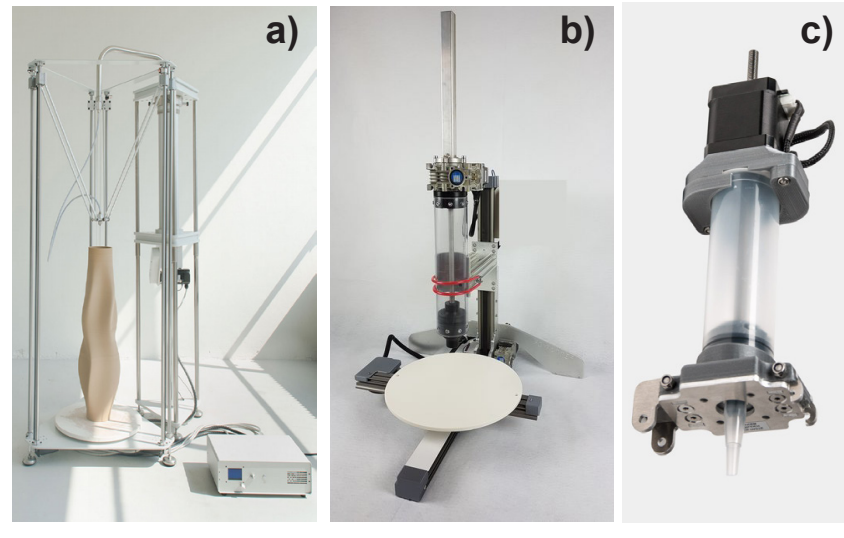

Figure 10: Images of Olivier van Herpt's 3D printing equipment (a) [33], Micro 9 3D Potter printer (b) [34], and ZMorph thick paste extruder (c) [35].

[Figura 10: Imagens do equipamento de impressão 3D de Olivier van Herpt (a) [33], impressora Micro 93 P Potter (b) [34] e extrusora de pasta espessa ZMorph (c) [35].] 
Pneumatic feeding + conventional screw. Claystruder 2: a second phase in the development of the Unfold design studio led them to build Claystruder 2 (Fig. 11a) in 2012. This was a two-step device: a $60 \mathrm{~cm}^{3}$ syringe connected to a compressed air line acted as a paste feed cartridge to a second step in which a conventional screw, driven by a stepper motor synchronized to the printer, forces the paste to flow through a nozzle. With this mechanism built using 3D printing and standard components, they managed to manufacture the first series of pieces of great formal complexity and high level of detail [38]. Auger extruder printhead: Jonathan Keep also incorporated into his delta printer a homemade two-step device (Fig. 12a), which had the same operation principle but greater capacity than that of Unfold. Despite the relative constructive precariousness, with this equipment, he produced works that were greatly recognized for the technical quality and innovative approach, such as the series of pots created from sound [29]. Lutum auger system: since 2012, the Dutch company VormVrij [39] offers its Lutum line of printers (Fig. 12b), cartridges, and extruders, which are among the most advanced designs on the market. The printer is Cartesian, its base forms a wide fixed platform, and the printhead is the one that moves on the 3 axes with a cantilever configuration that clears all obstacles from the work volume, $430 \times 460 \mathrm{~mm}$ in XY axes and 500 to 800 $\mathrm{mm}$ in the $\mathrm{Z}$-axis. The extruder is metal-coated for greater durability, excellent sealing, and easy assembly and cleaning [40]. It directly supports 650 and $1400 \mathrm{~cm}^{3}$ cartridges; however, it can use higher capacity cartridges but external to the printer and connected by a hose. It offers a double extruder version for two-material printing. The air pressure regulation system is integrated into the machine base. $L D M$ extruder: the collective known as the World's Advanced Saving Project (WASP) was formed in Ravenna, Italy. Its aim was the social diffusion of technological innovation. The construction of a delta printer at an architectural scale to print parts of houses through adobe extrusion was among the projects [37]. The knowledge obtained consolidated them as a reference for large scale industrial FDM 3D printers, particularly specialized in ceramics. The extrusion kit (Fig. 11b) in 2015 presented remarkable improvements with respect to previous homemade models. The first step consisted of a $3 \mathrm{~L}$ metal tank with two lids that facilitate loading and cleaning, connecting the airline by means of a pressure regulator that feeds the screw extruder through a hose by liquid deposition modeling (LDM) [37]. The LDM extruder is designed for simple assembly and easy cleaning and can be mounted on any printer. WASP currently offers delta printers in two sizes $(\phi 200 \times 400$ and $\phi 400 \times 1000 \mathrm{~mm})$, and its control software has specifically increased user-friendliness and incorporated specific improvements for 3D printing of ceramic paste. ClayXYZ: of the new generation of companies that started under the Kickstarter collaborative financing platform aimed at 3D printing of ceramics, ClayXYZ offers a screw extrusion system with pneumatic feeding by means of a specialized air compressor that ensures continuous flow and the removal of paste bubbles. The design of this new project that was started in New York in 2017 includes numerous advances in simplifying the operation to bring technology closer to non-specialized users [41]. Duraprinter: since 2018, the DuraCer Group, based in Rio de Janeiro, Brazil, offers its products to research and development centers, and to artists and artisans, under the trademark DuraPrinter [42]. It has 3 sizes of delta type printers with working volumes of 145 to $300 \mathrm{~mm}$ in diameter and 180 to $600 \mathrm{~mm}$ in height. The conventional screw extruder is provided with 2 to $10 \mathrm{~mm}$ nozzles and can also be mounted with standards dispensing needles, with a diameter varying from 0.26 to $1.8 \mathrm{~mm}$. The paste is transported to the extruder from a container, with capacities from 0.3 to $5.0 \mathrm{~L}$, pressurized by compressors or gas from a pressured cylinder (Fig. 13). DuraCer Group also provides an electromechanically feeding system, with capacity of $1.1 \mathrm{~L}$, that can operate since $0.1 \mathrm{~L}$. Observations: i) the pneumatic feed and screw extrusion system is not strictly volumetric: as the screw channel is a continuum, the feeder pressure is propagated towards the nozzle; therefore, for the same speed of screw rotation, the flow varies with the pressure of the first site; according to Dixon [43], the term 'viscosity metering pumps' provides a better definition for

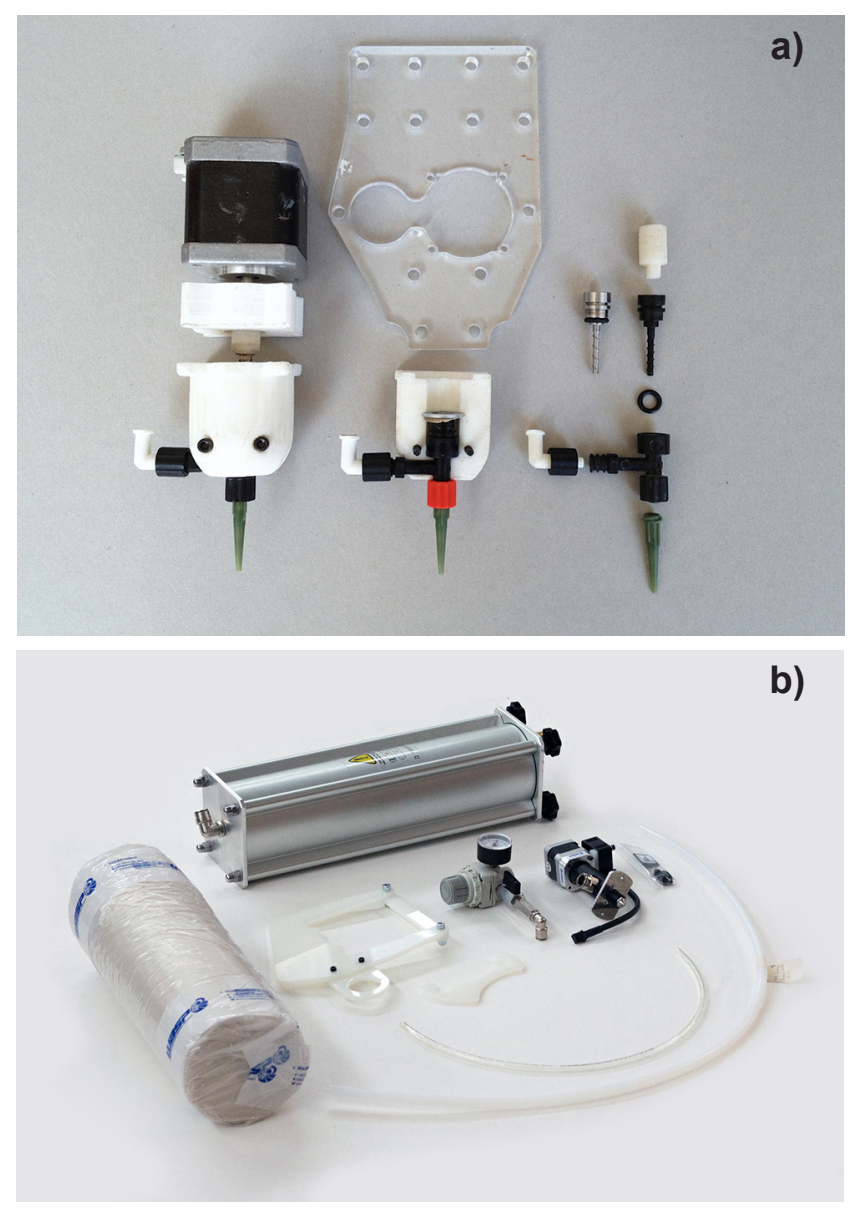

Figure 11: Images of Claystruder 2 (a) [36], and Wasp clay kit (b) [37].

[Figura 11: Imagens da Claystruder 2 (a) [36] e kit de argila da Wasp (b) [37].] 

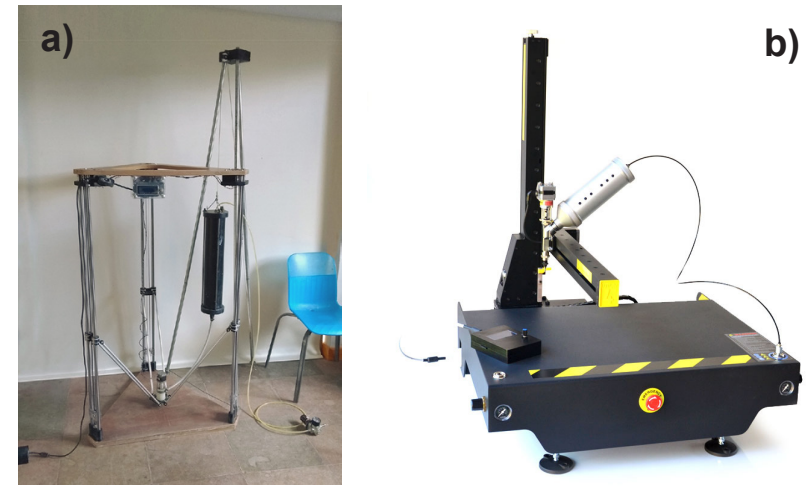

Figure 12: Images of delta printer with an auger extruder printhead (a) [29], and Lutum 3D printer (b) [39].

[Figura 12: Imagens da impressora delta com cabeçote de impressão de extrusora de rosca (a) [29] e impressora 3D Lutum (b) [39].]

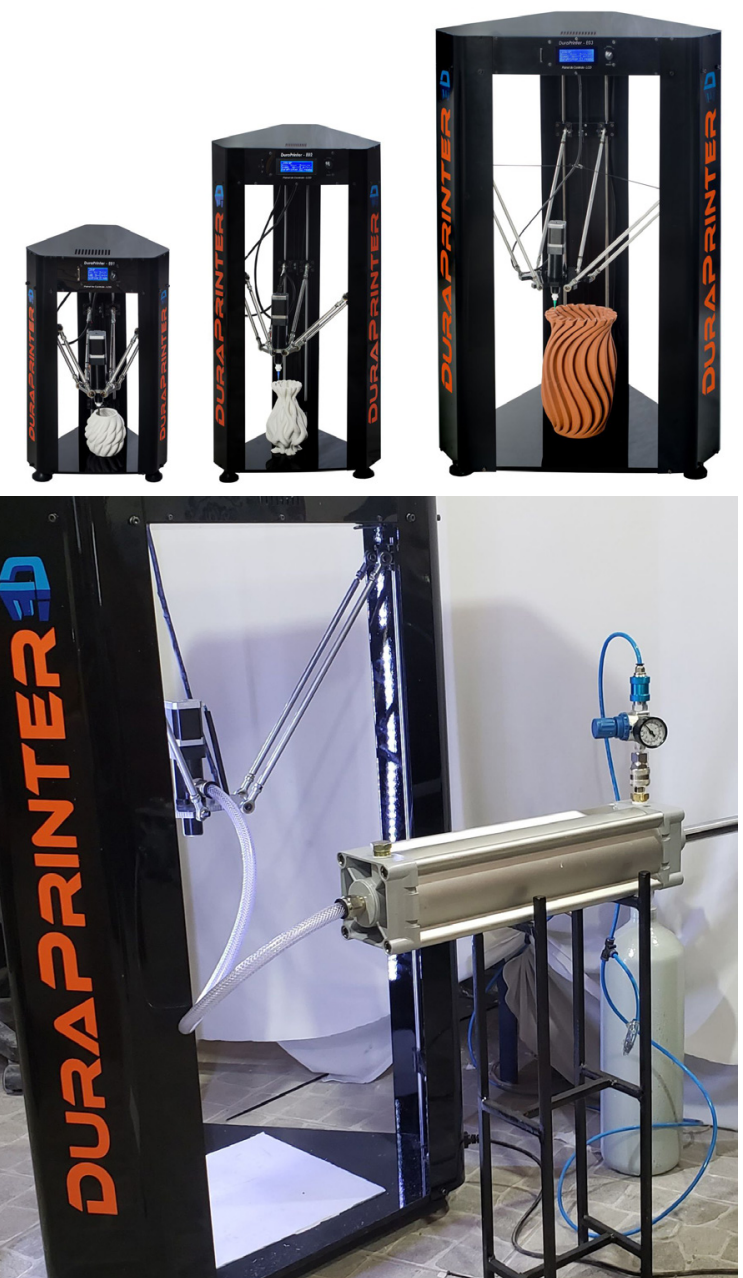

a)

b)

Figure 13: Images of DuraPrinter printers (a), and detail of the 2.5 $\mathrm{L}$ reservoir (b) [42].

[Figura 13: Imagens das impressoras DuraPrinter (a) e detalhe do reservatório de 2,5 L (b) [42].]

this device; ii) however, under constant conditions of paste viscosity, it is possible to achieve good control of the flow in the nozzle; thanks to the possibility of retraction by changing the screw rotation, it is possible to stop the extrusion fast and then restart it after an auxiliary movement; iii) under stable conditions, it is possible to print pieces of multiple walls and homogeneous fillings of the horizontal sides of the bottoms; and iv) with each new load and according to its viscosity, the air pressure must be regulated in calibration tests according to the programmed pass thickness.

Mechanic feed + conventional screw. Ram delivery + auger extruder: Tom Lauerman has recently published his advances in the construction of a synchronized auger extruder with a mechanical supply feed (Fig. 14a) [46]. After a few years of developing equipment and exploring the morphological possibilities of the process, this researcher at the Penn State University, College of Arts and Architecture in Pennsylvania, USA, and one of the main promoters of the Ceramic 3D Printing community, in 2016, achieved important advances in the synchronization of both stages by harnessing the ability of the Arduino and Ramps plates to control more than one extruder simultaneously, and which was previously developed for printing multicolored plastics by mixing filaments in multiple extruders. Mechanical clay feed: in 2017, Jonathan Keep published a mechanical feeder version (Fig. 14b) that replaces the pneumatic feeder and works in conjunction with the previous screw extruder. The feeder proved to be significantly large in relation to the loading capacity of the cartridge, and the elasticity of the used materials resulted in a complication in the synchronization of both motors [45]. StoneFlower: with a release in Kickstarter in 2018, StoneFlower, a project based in Munich, Germany, joins the market with its ceramic extrusion kit adaptable to any desktop 3D printer (Fig. 15a). The screw extruder design is based on previous versions of the maker community and is offered under an open license. Their main contribution is the design of a solid and practical mechanical piston for the feed process. The transparent plastic cartridge has a $500 \mathrm{~cm}^{3}$ capacity, a high torque motor allows to extrude low viscosity pastes, and an integrated control system ensures high precision in the process [47]. Cerambot: also, in 2018, the Cerambot company, from the city of Jinan, China, launched in Kickstarter its proposal for an extrusion kit adaptable to desktop printers. They offer, either jointly or independently, their delta printer and two alternative kits, a screw extruder fed pneumatically or mechanically (Figs. 15b and 15c). As the main improvement feature, they claimed to have achieved a faster and more precise system than previous versions [49]. Observations: i) unlike the previous type of pneumatic feeding, the mechanical feeding by means of a motorized screw/nut mechanism can be synchronized electronically and can solve the elasticity problems of the system; ii) the extrusion and retraction control makes it possible to print multiple-walled pieces and homogeneous fillings of the horizontal sides of the bottoms; iii) an external compressed air source is not required; iv) the same size of the cartridge as the pneumatic feeding allows to achieve greater thrust forces of the piston and, therefore, to work with denser pastes enabling to obtain pieces with greater resistance to support their own weight and the efforts during deposition; and v) the feeding device 

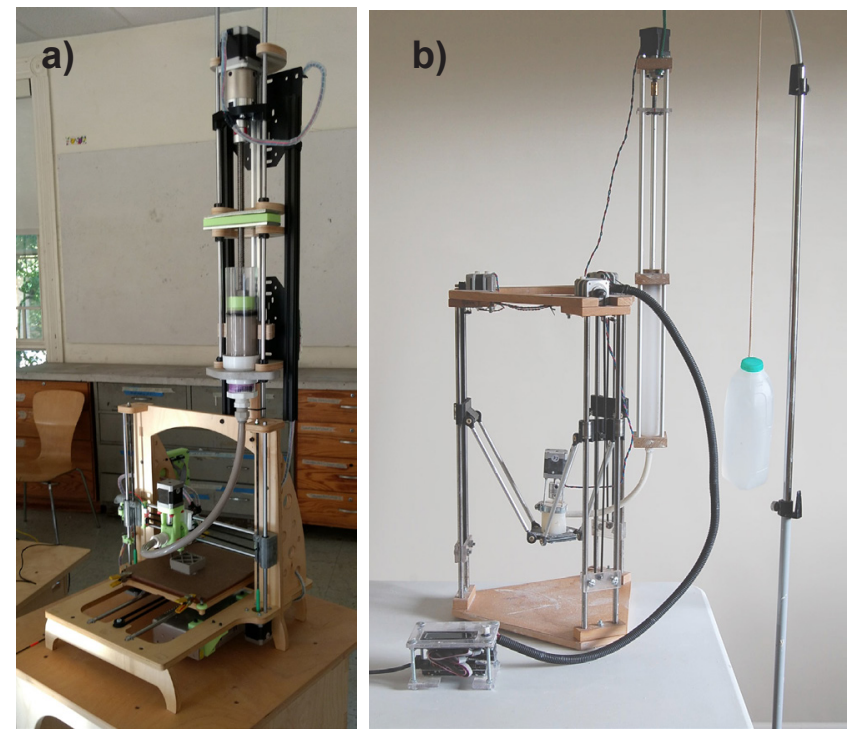

Figure 14: Images of Tom Lauerman's 3D printer with ram delivery + auger extruder (a) [44], and delta printer with mechanical clay feed (b) [45].

[Figura 14: Imagens da impressora 3D de Tom Lauerman com pistão móvel + extrusora de rosca (a) [44] e impressora delta com alimentação mecânica de argila (b) [45].]

is bulky and heavy, and the high torque gearbox requires power electronics.

Pneumatic feed + endless piston. Moineau stepper extruder: in the search for a completely volumetric device, Dries Verbruggen and Claire Warner from Unfold focused their research on the principle of progressive cavity pumps. Their first attempt was in 2012 with a device printed in plastic based on an open access design, fed with a standard $60 \mathrm{~cm}^{3}$ syringe driven by compressed air (Fig. 16a). With this experience, they were able to validate the operation principle, but also encountered the FDM limitations with regard to the strength of the pieces and the dimensional adjustment of the assembly [50]. Unfold ViscoTec progressive cavity pump: in
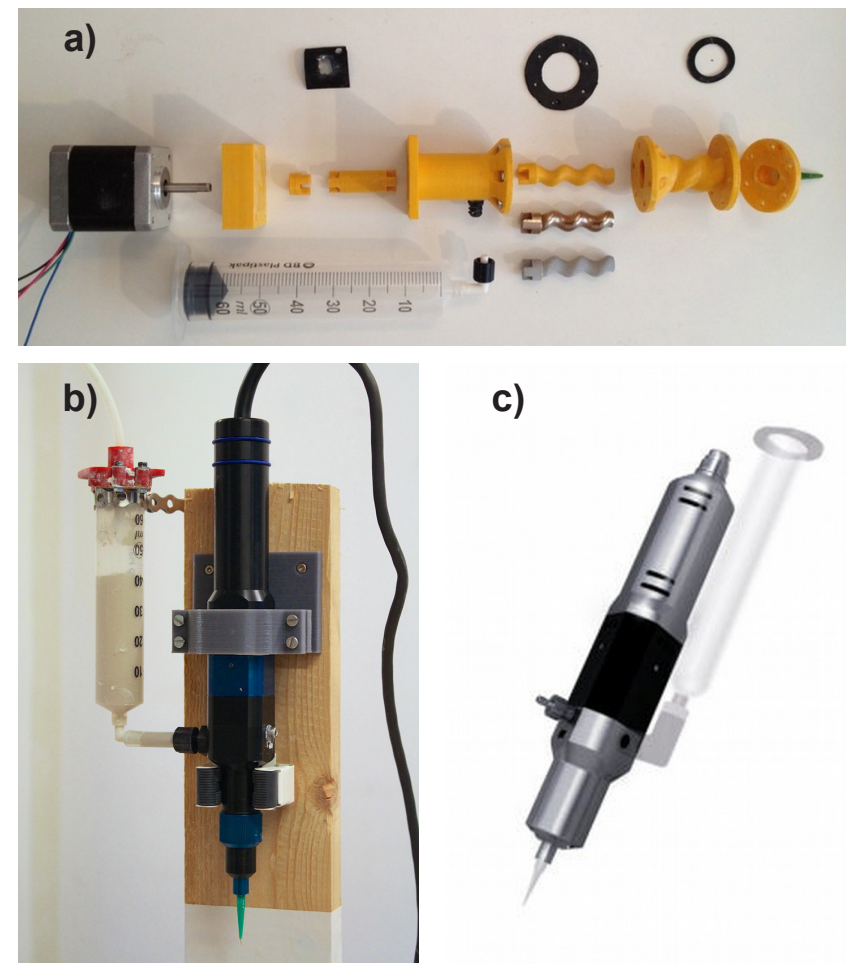

c)

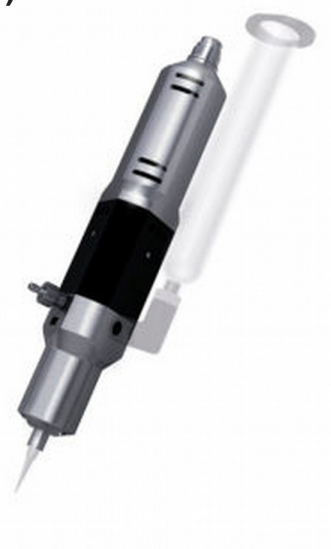

Figure 16: Images of Moineau stepper extruder (a) [50], Unfold ViscoTec progressive cavity pump (b) [51], and Vipro-head (c) [52].

[Figura 16: Imagens da extrusora deslizante Moineau (a) [50], bomba de cavidade progressiva Unfold ViscoTec (b) [51] e Vipro-head (c) [52].]

2014, Verbruggen in association with the German company ViscoTec, a global leader in dosing solutions, tested an industrial quality endless piston extruder adapted to ceramics with a pneumatic feed, achieving excellent results in extrusion control at different speeds (Fig. 16b) [51]. Vipro-head: in 2014, the ViscoTec launched into the market a specific endless piston extruder for 3D printing. The Viprohead (Fig. 16c) is a compact and precise, progressive cavity
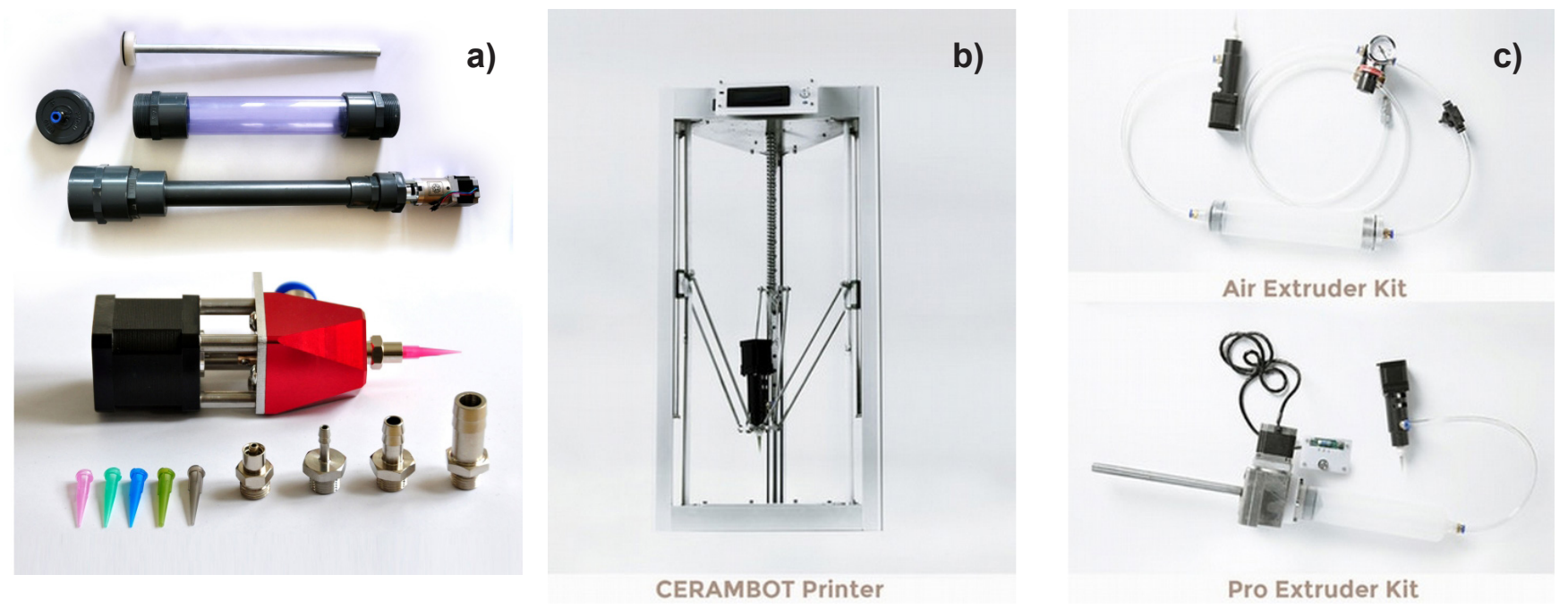

Figure 15: Images of StoneFlower feeder and extruder (a) [47], Cerambot's printer (b), and pneumatic and mechanical kits (c) [48]. [Figura 15: Imagens do alimentador e extrusor StoneFlower (a) [47], impressora da Cerambot (b) e seus kits pneumáticos e mecânicos (c) [48].] 
pump for extruding pastes and viscous materials and can be mounted on desktop 3D printers [52]. It allows extruding in very small diameters to achieve very detailed pieces. It has temperature control and a double feed version for mixing two-component materials. Its high-cost and size limitation makes it more applicable in bioprinting and research of materials than in the production of standard ceramic pieces. Observations: i) progressive cavity pumps are completely volumetric; therefore, extrusion is independent of the viscosity of the material; ii) the transmission between motor and endless piston must be that of a double Cardan joint, quite more complex than the simple direct transmissions of other mechanisms; iii) the helical metallic rotor and the double helix elastic stator are formally complex pieces with high dimensional precision, which are thus complex to be built, requiring highly specialized production technologies such as $\mathrm{CNC} 4^{\text {th }}$ axis machining; and iv) previously existing components must be mounted on the moving parts of the printer, which limits the weight of the device and its load capacity, making it a suitable technique for high-value-added materials and small parts that require good dimensional resolution.

\section{FINAL COMMENTS}

In relation to other ceramic additive manufacturing (AM) techniques, the paste deposition modeling (PDM) exhibits, on the one hand, deficiencies in terms of dimensional precision, morphological complexity, and optimum use of advanced materials and, on the other hand, important advantages in terms of the size of the pieces, shorter manufacturing times, lower costs and better availability of inputs, cheaper equipment and easier maintenance, a higher level of innovation advance in everyday applications, and an important diffusion of technological and scientific knowledge in society and industry. In view of the existing background in this topic, it can be affirmed that artisanal ceramic pottery and the industrial production of traditional ceramics are indeed entering their digital stage with the development of PDM, as is happening in other technological fields. However, in order to consolidate these budding innovations, it is necessary to face several challenges, some of which are strictly technological and others are related to product design and the search for new applications. Paste formulation and preparation must be improved in order to achieve more stable, predictable, and repeatable process conditions. The deaeration of raw materials, which had already been solved in traditional industrial processes, is often a frequent problem. Water is the only solvent used to achieve adequate rheology; the exploration of other plasticizing components could facilitate extrusion, improve the piece strength during deposition, and bring benefits in the drying process. Research on pastes based on advanced materials could solve some of the difficulties of clay pastes and would open the technology to high value-added applications. The integration of ceramic paste extruders in systems designed for plastics requires greater adaptation.
The range of behavior of a clay paste obtained in an artisanal or industrial way, not exclusively in a laboratory, is much greater than that of the polymer filaments available for the fused deposition modeling (FDM). The plasticity of the material can vary, not only between one batch and another but during the same load, which is indeed a problem for an open-loop control system. The field of product design faces the challenge of the exploration of morphologies harnessing the characteristic features of the process to create new products with their own expressive attributes, proposing new shapes to everyday products, and also expanding the uses and applications of ceramics.

\section{ACKNOWLEDGMENTS}

The authors would like to thank the Universidad Nacional de Lanús and the Consejo Nacional de Investigaciones Científicas y Técnicas for their support. This work has been partially funded by the Project of Oriented Research 'Desarrollo de una tecnología de impresión 3D por sistema de extrusión-deposición de materiales cerámicos', PIO CONICET-UNLa 2016-2018, No. 22420160100023CO.

\section{REFERENCES}

[1] J.M. Fressoli, A. Smith, Integración Comercio 19, 39 (2015) 112.

[2] T. Wohlers, T. Gornet, "History of additive manufacturing", Wohlers Report (2016).

[3] Y. Huang, M.C. Leu, J. Mazumder, A. Donmez, J. Manuf. Sci. Eng. 137 (2015) 14001.

[4] N. Gershenfeld, Foreign Aff. 91 (2012) 16.

[5] ISO/ASTM 52900, "Additive manufacturing, general principles, terminology", ISO (2015).

[6] N. Travitzky, A. Bonet, B. Dermeik, T. Fey, I. FilbertDemut, L. Schlier, T. Schlordt, P. Greil, Adv. Eng. Mater. 16 (2014) 729.

[7] 3D Hubs, "Additive manufacturing technologies", https://www.3dhubs.com, ac. 15/03/2019.

[8] J. Deckers, J. Vleugels, J.-P. Kruth, J. Ceram. Sci. Technol. 5 (2014) 245.

[9] A. Zocca, P. Colombo, C.M. Gomes, J. Günster, J. Am. Ceram. Soc. 98 (2015) 1983.

[10] Z. Chen, Z. Li, J. Li, C. Liu, C. Lao, Y. Fu, C. Liu, Y. Li, P. Wang, Y. He, J. Eur. Ceram. Soc. 39 (2019) 661.

[11] Slic3r, "Manual, flow math", https://slic3r.org, ac. 15/03/2019.

[12] W.M. Carty, U. Senapati, J. Am. Ceram. Soc. 81 (1998) 3.

[13] C.B. Carter, M.G. Norton, Ceramic materials science and engineering, $2^{\text {nd }}$ ed., Springer, New York (2013) 713.

[14] F.A. Andrade, H.A. Al-Qureshi, D. Hotza, Appl. Clay Sci. 51 (2011) 1.

[15] W.E. Brownell, Structural clay products, SpringerVerlag, Wien (1976).

[16] Wikifactory, "Ceramic 3D printing", https://wikifactory. com/+Ceramic3DPrinting, ac. 15/06/2019. 
[17] F. Handle (Ed.), "Extrusion in ceramics", Springer (2007).

[18] P. Swanson, “The 'endless piston' pump technology for precision dispensing", Process Control Today (2012) http:// www.pandct.com.

[19] J. Gravesen, Comput. Aided Geom. Des. 25 (2008) 792. [20] F. Bergaya, G. Lagaly (Eds.), "Handbook of clay science", $2^{\text {nd }}$ ed., Elsevier (2013).

[21] F. Bergaya, G. Lagaly, in "Developments in clay science", Eds. F. Bergaya, B.K.G. Theng, G. Lagaly, 1, Elsevier (2006) 1.

[22] G. Hodgson, "A history of RepRap development" (2012) https://reprap.org/mediawiki/images/a/a5/A_ History_of_RepRap_Development.pdf.

[23] Unfold, "Claystruder 1.1" (2010) https://www. thingiverse.com/thing:3604.

[24] D. Verbruggen, RepRap Magazine 3 (2014) 26.

[25] Unfold Fab, "Design for the extruder (on short hold)" (2009) https://unfoldfab.blogspot.com.

[26] Unfold, "Claystruder 1.5" (2012) https://www. thingiverse.com/thing:21788.

[27] J. Keep, "Ceramic delta 3D printer" (2013) https:// www.thingiverse.com/thing: 147055 .

[28] Unfold Fab, "Road to better paste extrusion, episode 1: recap" (2012) https://unfoldfab.blogspot.com.

[29] J. Keep, "Make your own 3D delta printer for ceramic", http://www.keep-art.co.uk/Self_build.html, ac. 27/03/2019.

[30] Hodlipson, "Fab@Home model2 3D printer and printed parts” (2010) https://en.wikipedia.org/wiki/File:Fab@ Home_Model_2_3D_printer.jpg.

[31] E. Malone, H. Lipson, Rapid Prototyp. J. 13 (2007) 245. [32] J.I. Lipton, D. Cohen, M. Heinz, M. Lobovsky, W. Parad, G. Bernstein, T. Li, J. Quartiere, K. Washington, A.A. Umaru, R. Masanoff, J. Granstein, J. Whitney, H. Lipson, in Proc. Solid Freeform Fabricat. Symp., Austin (2009) 70.

[33] O. van Herpt, "Explorations in functional 3D printing ceramics", http://oliviervanherpt.com/functional-3dprinted-ceramics, ac. 01/04/2019.

[34] 3D Potter, "Micro 9", https://3dpotter.com, ac. 01/04/2019.

[35] ZMorph, "Thick paste extruder", https://zmorph3d. com, ac. 01/04/2019.

[36] Unfold, "Claystruder 2, auger paste extruder" (2012) https://www.thingiverse.com/thing:28018.
[37] Wasp, "Stampanti 3D", https://www.3dwasp.com, ac. 01/04/2019.

[38] Unfold Fab, "Road to better paste extrusion, episode 2: auger valves" (2012) https://unfoldfab.blogspot.com.

[39] VormVrij, "Lutum, 3D clay printer", https://vormvrij. nl, ac. 01/04/2019.

[40] Y. van den Heerik, "Development of the Lutum ${ }^{\circledR}$ Auger system", 3D Clay Printing (2017) https://3dclayprinting. com.

[41] ClayXYZ, "Desktop 3D clay printer, create your own artwork!", https://www.kickstarter.com/projects/clayxyz/ clayxyz-desktop-3d-clay-printer-create-your-own-ar, ac. 01/04/2019.

[42] DuraPrinter 3D, "3D printers for ceramics", https:// duraprinter3d.com/en/, ac. 09/04/2020.

[43] D. Dixon, Archimedes Pumps, (1996). http://www3. uic.com/wcms/images2.nsf/(GraphicLib)/Archimedes_ Pumps.PDF.

[44] T. Lauerman, "Clay printer" (2016) https://photos.app. goo.gl/d59RjAG6xDCWf1yZ9.

[45] J. Keep, "Make your own clay auger printhead with mechanical ram delivery" (2017) http://www.keep-art. co.uk/printhead.html.

[46] T. Lauerman, "3D printing in clay: using a synchronized auger extruder with a mechanical supply feed" (2019) https://tomlauerman.com/blog.

[47] StoneFlower, "Ceramic 3D printer", https://www. stoneflower3d.com, ac. 01/04/2019.

[48] Cerambot, "The most affordable ceramic 3D printer", https://www.kickstarter.com/projects/210413417/cerambotthe-most-affordable-ceramic-3d-printer, ac. 14/12/2019.

[49] Cerambot, "The most affordable ceramic 3D printer", https://www.cerambot.com, ac. 01/04/2019.

[50] Unfold, "Moineau stepper extruder Luer lock updates" (2012) https://www.thingiverse.com/thing:16741.

[51] Unfold Fab, "Road to better paste extrusion, episode 3: industrial quality 3D printing of paste materials with ViscoTec Moineau pump" (2014) https://unfoldfab.blogspot. com.

[52] Viscotec Pumpen, "3D printing: fluids \& paste printing with 3D print heads based on endless piston principle", https://www.viscotec.de, ac. 01/04/2019.

(Rec. 06/01/2020, Rev. 15/04/2020, 08/05/2020, Ac. $11 / 05 / 2020)$ 